\title{
Efeitos de um curso de meditação de atenção plena em estudantes da saúde no Brasil
}

Effects of a mindfulness meditation course on healthcare students in Brazil Efectos de un curso de meditación de atención plena en estudiantes de la salud en Brasil

\author{
Aline Corrêa de Araujo ${ }^{1}$ ie https://orcid.org/0000-0002-6420-4606 \\ Carmen Lúcia Albuquerque de Santana ${ }^{1}$ id https://orcid.org/0000-0002-6148-6230 \\ Elisa Harumi Kozasa ${ }^{1}$ id https://orcid.org/0000-0003-4723-6099 \\ Shirley Silva Lacerda ${ }^{1}$ in hitps://orcid.org/0000-0002-2370-6693 \\ Luiza Hiromi Tanaka' io hitps://orcid.org/0000-0003-4344-1116
}

\section{Como citar:}

Araujo AC, Santana CL, Kazasa EH, Lacerda SS, Tanaka LH. Efeitos de um curso de meditação de atenção plena em estudantes da saúde no Brasil. Acta Paul Enferm. 2020;33:APE20190170.

DOI

http://dx.doi.org/10.37689/actaape/2020A00170

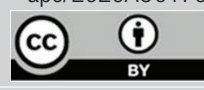

Descritores

Estudantes; Ocupação em saúde; Atenção plena; Meditação; Promoção da saúde

Keywords

Students; Health occupations; Mindfulness; Meditation; Health promotion

Descriptores

Estudiantes; Empleos en salud; Atención plena Meditación; Promoción de la salud

\section{Submetido}

16 de julho de 2019

Aceito

21 de outubro de 2019

\section{Autor correspondente}

Aline Corrêa de Araujo https://orcid.org/0000-0002-6420-4606

\section{Resumo}

Objetivo: Avaliar os efeitos de um curso de meditação de atenção plena nas emoções e na gentileza dos estudantes de Saúde em relação a si mesmos e aos outros.

Métodos: Estudo de caso longitudinal e de método misto com inclusão de ferramentas quantitativas e qualitativas. Os grupos de controle $(n=14)$ e de estudo $(n=16)$ foram formados por uma população de 30 estudantes de Enfermagem, Medicina e Fonoaudiologia. Os participantes do grupo de estudo fizeram curso eletivo sobre estratégias para desenvolver a atenção plena incluindo varredura corporal, respiração consciente e movimento consciente, entre outros. Durante as aulas, os alunos também participaram de discussões sobre gentileza e compaixão, com base em espiritualidade e neurociência. 0 curso teve duração de 36 horas, ao longo de nove semanas. Os alunos dos grupos de estudo e controle foram avaliados por meio de entrevistas em grupo, antes e após o curso. As ferramentas de avaliação incluíram a Escala de Estresse Percebido (PSS), a Escala de Atenção Plena e Consciência (MAAS), a Escala de Afeto Positivo e Negativo X (PANAS-X); e o Índice de Bem-Estar OMS-5. Resultados: Após o curso, os indivíduos do grupo de estudo alcançaram pontuações significativamente mais baixas no PANAS-X (afeto negativo) em comparação com as pontuações anteriores. Outras variáveis quantitativas não tiveram alterações significativas $(p>0,05)$. Três categorias emergiram das análises qualitativas: (a) dificuldades em viver o momento presente e ansiedade na tentativa de controlar o futuro; (b) práticas de meditação como ferramenta para enfrentar tais dificuldades; e (c) experiência caracterizada pelo afeto.

Conclusão: 0 curso eletivo focado na meditação da atenção plena e compaixão ajudou a desenvolver as habilidades socioemocionais de bem-estar, a autoconsciência dos alunos e a reduzir 0 afeto negativo.

\section{Abstract}

Objective: To evaluate the effects of a course on mindfulness meditation practices on healthcare students in relation to their emotions and kindness to themselves and others.

Methods: Mixed method, longitudinal case study including quantitative and qualitative tools. A population of 30 nursing, medical, and phono-audiology students formed the study $(n=16)$ and control $(n=14)$ groups. Students in the former group took an elective course on strategies for the development of mindfulness, which included body scans, conscious breathing, and conscious movement, among others. During classes, students also participated in dialogues about kindness and compassion with a basis on spirituality and neuroscience. The course lasted 9 weeks, totaling 36 hours. Students in both the study and control groups were evaluated trough group interviews before and after the course took place. Evaluation tools included the Perceived Stress Scale (PSS); Mindful Attention Awareness Scale (MAAS); Positive and Negative Affect Schedule X (PANAS-X); and the WHO-5 Well-Being Index. 
Results: Individuals in the study group had significantly lower scores on the PANAS-X (negative affect) after the course, in comparison with their previous scores. Other quantitative variables were not significantly altered $(p>0.05)$. Qualitative analyses yielded three categories: (a) difficulties living the present moment and anxiety trying to control the future; (b) meditation practices seen as a tool for facing such difficulties; and (c) experience characterized by affection.

Conclusion: The elective course focused on mindfulness meditation and compassion developed socio-emotional, well-being and self-awareness abilities in the students, and reduced negative affect.

\section{Resumen}

Objetivo: Evaluar los efectos de un curso de meditación de atención plena en las emociones y gentileza de estudiantes de la salud con relación a sí mismos y a los otros.

Métodos: Estudio de casos longitudinal y de método mixto con inclusión de herramientas cuantitativas y cualitativas. Una población de 30 estudiantes de Enfermería, Medicina y Fonoaudiología formaron los grupos de control $(n=14)$ y experimental $(n=16)$. Los participantes del grupo experimental hicieron un curso electivo sobre estrategias para desarrollar la atención plena, que incluyó exploración corporal, respiración consciente y movimiento consciente, entre otras. Durante las clases, los alumnos también participaron en discusiones sobre gentileza y compasión, basadas en espiritualidad y neurociencia. El curso tuvo una duración de 36 horas, durante nueve semanas. Se evaluó a los alumnos de los grupos experimentales y de control mediante entrevistas en grupo, antes y después del curso. Las herramientas de evaluación incluyeron la Escala de Estrés Percibido (PSS), la Escala de Conciencia y Atención Plena (MAAS), la Escala de Afecto Positivo y Negativo X (PANAS-X) y el Índice de Bienestar OMS-5.

Resultados: Después del curso, los individuos del grupo experimental alcanzaron una puntuación significativamente más baja en la PANAS-X (afecto negativo) en comparación con la puntuación anterior. Otras variables cuantitativas no tuvieron modificaciones significativas ( $p>0,05)$. Surgieron tres categorías de los análisis cualitativos: (a) dificultades de vivir el momento presente y ansiedad en el intento de controlar el futuro; (b) prácticas de meditación como herramienta para afrontar tales dificultades; y (c) experiencia caracterizada por el afecto.

Conclusión: El curso electivo dedicado a la meditación de atención plena y compasión ayudó a desarrollar habilidades socioemocionales de bienestar y la autoconciencia de los alumnos y a reducir el afecto negativo.

\section{Introdução}

Os estudantes de saúde geralmente experimentam altos níveis de estresse durante a vida acadêmica, que podem resultar em sentimentos de autocrítica e baixa autoestima. ${ }^{(1-3)}$ Esses estudantes desenvolvem afeto negativo (AN) e condiçóes como síndrome do intestino irritável e depressão. O sofrimento psicológico vivenciado, combinado a sentimentos negativos, tem forte impacto na qualidade de vida e pode levar a alteraçôes de humor, desespero e ansiedade. ${ }^{(4,5)}$ Estudos anteriores mostraram que práticas meditativas, aprendizado estruturado de autoconsciência e técnicas de relaxamento impactam positivamente vários aspectos emocionais dos estudantes de Saúde. Na busca por referências que embasaram este trabalho, não foram encontrados artigos sobre os efeitos da inclusão de práticas de atenção plena no currículo de Saúde das universidades brasileiras.

A Organização Mundial da Saúde (OMS) declarou que a promoção do bem-estar é tão importante quanto a redução de doenças mentais. ${ }^{(6)}$ Isto sugere a necessidade de estratégias de prevenção novas e eficazes, as quais podem ser representadas por práticas meditativas de atençáo plena. Segundo Kabat$\mathrm{Zinn}^{(7)}$ essa forma de meditação "emerge ao prestar atenção no momento presente com propósito e sem julgamento, no desdobramento da experiência momento a momento" e enfatiza a transitoriedade das experiências. A prática envolve a regulação da atenção e do foco no momento presente com gentil curiosidade, abertura e aceitação. A meditação da atenção plena promove a sensaçáo subjetiva de bem -estar, vitalidade, controle emocional adaptativo, estabilidade comportamental e níveis mais baixos de afeto negativo e de sintomas psicopatológicos. ${ }^{(8)}$

Cada vez mais, a prática meditativa tem sido vista como um suporte emocional para os estudantes de Saúde, principalmente para ajudar a gerenciar o estresse, fornecer apoio emocional e ensinar o foco atencional. ${ }^{(9,10)}$ Alguns estudos sugerem a inserção dessas práticas no currículo formal. ${ }^{(11,12)}$ Cursos de graduação em Ciências da Saúde, como os da Universidade Monash, na Austrália, e a Faculdade de Medicina e Odontologia de Rochester, nos EUA, também promoveram disciplinas eletivas semelhantes às relatadas neste estudo. ${ }^{(13,14)}$ Avaliamos os efeitos de um curso de meditaçáo de atenção plena nas emoçóes e gentileza dos estudantes de Saúde em suas relaçóes consigo próprios e com os outros.

\section{Métodos}

Estudo de caso, longitudinal e de método misto, que incluiu ferramentas quantitativas e qualitativas, 
baseado na teoria de Yin. ${ }^{(15)} \mathrm{O}$ estudo foi aprovado pelo Comitê de Ética em Pesquisa sob o número 1.150.962.

Os participantes são estudantes de Medicina, Enfermagem e Fonoaudiologia de uma universidade pública de São Paulo. Todos aceitaram participar do estudo, se matricular no curso eletivo e ter uma frequência mínima de $85 \%$ nas aulas. $\mathrm{O}$ grupo de controle contemplou estudantes voluntários da mesma classe e universidade que os colegas do grupo de estudo. Os estudantes do grupo de controle não fizeram o curso eletivo e aceitaram responder aos formulários antes e depois do curso. Os alunos do grupo de controle se voluntariaram em cada sala de aula de graduação, após o convite pessoal do pesquisador. $\mathrm{O}$ critério de exclusão adotado foi o não preenchimento dos formulários.

Inicialmente, o grupo de estudo incluiu 24 estudantes, mas oito foram excluídos. A idade média foi de 21,8 anos, variando entre 19 e 30 anos. O grupo de controle inicialmente incluiu 26 alunos, mas 12 foram excluídos. A idade média foi de 20,8 anos, variando entre 18 e 24 anos (Figura 1).

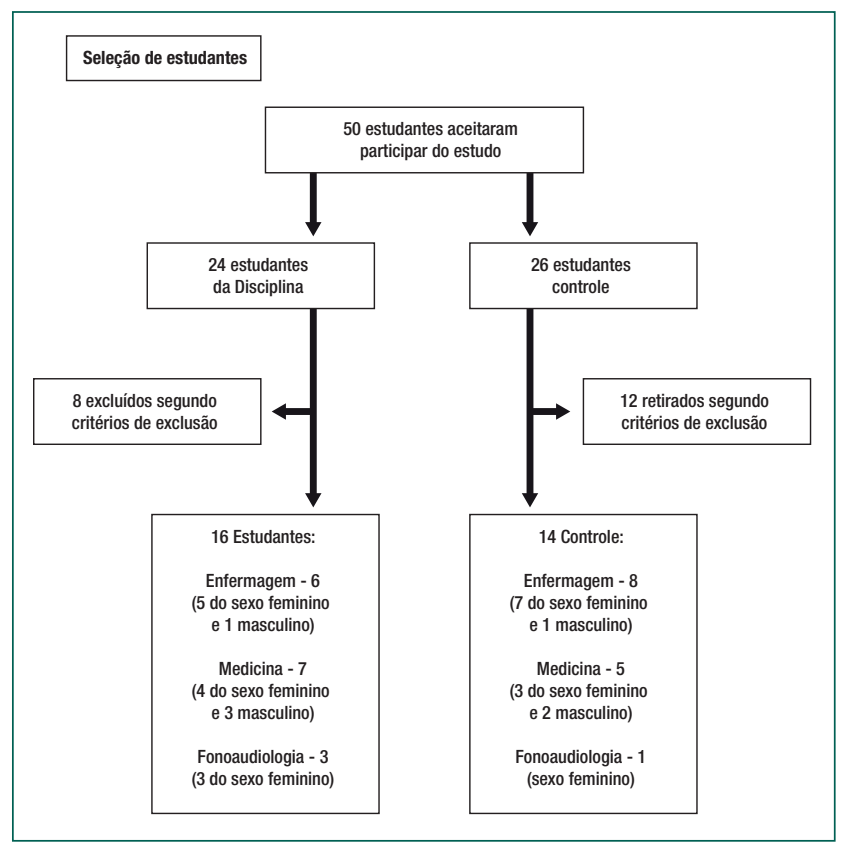

Figura 1. Fluxograma dos participantes do estudo

A universidade deste estudo oferece opçóes de cursos eletivos, com o objetivo de adicionar conteúdo e competências relevantes ao currículo. Além de frequentar as principais aulas, obrigatórias, os alunos escolhem livremente os cursos eletivos. "Práticas de atenção plena para a promoção de saúde integral baseadas na espiritualidade e neurociência" foi incluído no menu de cursos eletivos oferecidos.

\section{Procedimentos}

O curso eletivo teve início em agosto de 2015 e duração de nove semanas, com uma aula semanal, totalizando 36 horas. A inscrição foi oferecida aos alunos e havia 25 vagas disponíveis. Cada aula, de quatro horas, incluiu as atividades descritas no apêndice 1. A informação disponível na visão geral do curso era: "Apresentação dos conceitos e princípios de espiritualidade e neurociência para a prática da atenção plena e concentraçáo que promovem uma boa saúde integral. Debates sobre a necessidade de perceber, identificar e lidar com emoçôes, e sobre o conhecimento de como as emoçóes se originam, são processadas e afetam a mente. Análise das práticas de meditação que acalmam a mente, relaxam o corpo e promovem gentileza, autocompaixáo e compaixão para com o próximo. Desenvolvimento de um entendimento de espiritualidade e neurociências com listas de leitura recomendadas e apresentação de palestras sobre espiritualidade e saúde integral". O programa do curso incluía uma seção teórica e uma seção prática de meditação. Todas as aulas, incluindo meditaçóes e entrevistas, foram conduzidas pelo mesmo professor. Ao longo do curso, o primeiro autor deste artigo foi observador participante, gravou e transcreveu as entrevistas. Os alunos foram convidados a participar do estudo, o que exigiu responder quatro formulários de avaliação psicométrica e participação em duas entrevistas (no primeiro e no último dia de aula). Nenhum dos alunos abandonou o curso.

\section{Ferramentas quantitativas}

No primeiro e no último dia de aula, os alunos dos dois grupos foram avaliados com o uso de quatro ferramentas quantitativas validadas para o português, que mediram: percepção de estresse, atenção, afeto negativo, afeto positivo e bem-estar. As ferramentas de avaliação incluíram a Escala de Afeto Positivo e Negativo X (PANAS-X); ${ }^{(16)}$ Escala de 
Atenção Plena e Consciência (MAAS); ${ }^{(17)}$ Escala de Estresse Percebido (PSS); ; $^{(18)}$ e o Índice de BemEstar OMS-5 (WHO-5). ${ }^{(19)}$ Cada aluno respondeu ao PANAS-X, que inclui os seguintes 60 itens: Afeto Positivo (10 itens); afeto positivo básico, incluindo jovialidade, autoconfiança e atenção (11 itens); Afeto Negativo (10 itens); afeto negativo básico, incluindo medo, hostilidade, culpa e tristeza (15 itens); e outros estados afetivos, incluindo timidez, fadiga, serenidade e surpresa (14 itens). Cada item continha os adjetivos e as respostas foram fornecidas em uma escala Likert de 5 pontos. Os alunos também responderam individualmente ao MAAS, um instrumento com 15 itens avaliados em uma escala Likert de 6 pontos, variando de quase sempre atento a quase nunca atento. Os alunos responderam individualmente ao PSS, que contém 10 itens avaliados em uma escala Likert variando de $0 /$ nunca a $4 / \mathrm{com}$ muita frequência, onde pontuaçóes mais altas correspondem a níveis mais altos de estresse. Finalmente, a OMS-5 foi usada para avaliar como os participantes do estudo se sentiram nas duas semanas anteriores em uma escala de $0 /$ nunca a $5 / 0$ tempo todo, onde pontuaçôes mais altas representavam mais bem-estar.

\section{Análise estatística}

As respostas dos alunos foram compiladas em uma planilha Excel e analisadas com o software IBM SPSS, versão 22.0. As comparaçóes entre os grupos de controle e de estudo foram realizadas com o quiquadrado e o teste T de Student, e as comparaçóes entre e dentro dos grupos foram realizadas com medidas repetidas MANOVA. Diferenças com $\mathrm{p}<0,05$ foram consideradas significativas.

\section{Coleta e análise qualitativa de dados}

Os aspectos qualitativos do estudo foram baseados em entrevistas em grupo, realizadas no primeiro e no último dia do curso eletivo. As entrevistas foram gravadas e transcritas pelo pesquisador, que atuou como observador participante do curso. Não houve avaliador cego. As informaçóes foram estudadas por meio de análise de dados categórica e temática. ${ }^{(20)}$ As perguntas feitas na primeira entrevista incluíram: a) Por que você optou por fazer este curso? b) Como você se percebeu emocionalmente? As perguntas feitas na segunda entrevista incluíram: a) Como você está se sentindo sobre suas emoçóes? b) Como você avalia o curso? $\mathrm{O}$ autor transcreveu totalmente as entrevistas e conduziu a análise em quatro etapas, a saber: 1 leitura atenta e repetitiva da transcrição em busca do significado subjacente dos dados; 2 - compilação de dados em planilha do Excel; 3 - análise comparativa dos dados em busca de semelhanças e diferenças; 4 - síntese de dados na forma de expressóes, temas, padrôes e categorias de hipóteses. Além disso notas qualitativas sobre o humor e a atmosfera predominantes na classe foram registradas em um diário de campo.

\section{Resultados}

A tabela 1 mostra o perfil sociodemográfico dos participantes dos grupos de estudo e controle. As mulheres representaram $75 \%$ do grupo de estudo e $78 \%$ do grupo de controle, uma diferença que não foi significativa $(\mathrm{p}=0,825)$.

Tabela 1. Características sociodemográficas dos grupos de estudo e controle

\begin{tabular}{lcc}
\hline Dados sociodemográficos & $\begin{array}{c}\text { Grupo de estudo } \\
(\mathbf{n}=16)\end{array}$ & $\begin{array}{c}\text { Grupo de controle } \\
(\mathbf{n}=14)\end{array}$ \\
\hline Solteiro & $15 / 16$ & $12 / 13^{*}$ \\
Faixa etária 18-24 & $14 / 16$ & $13 / 13^{\star}$ \\
Faixa etária 25-30 & $2 / 16$ & $0^{*}$ \\
Masculino & $4 / 16$ & $3 / 14$ \\
Feminino & $12 / 16$ & $11 / 14$ \\
Usuários de transporte público & $10 / 16$ & $5 / 6^{\star}$ \\
Estudantes de enfermagem & $6 / 16$ & $8 / 14$ \\
Estudantes de medicina & $7 / 16$ & $5 / 14$ \\
Estudantes de fonoaudiologia & $3 / 16$ & $1 / 14$ \\
Conhecimento prévio de meditação & 0 & $0^{*}$ \\
Problemas de saúde & $4 / 16$ & $1 / 6^{*}$ \\
\hline
\end{tabular}

*Alguns participantes do grupo de controle não responderam a todas as perguntas sociodemográficas

\section{Resultados quantitativos}

$\mathrm{Na}$ aplicação dos instrumentos PANAS-X, MAAS, EEP e OMS-5 antes do curso, não foram encontradas diferenças significativas entre os grupos de controle e estudo, independente da ferramenta utilizada $(\mathrm{p}>0,05)$ (Tabela 2).

As medidas repetidas MANOVA foram aplicadas para testar o efeito do curso eletivo sobre variáveis ao longo do tempo. Não encontramos diferenças entre os grupos de estudo e controle em 
Tabela 2. Comparação das pontuações obtidas nos grupos de estudo e controle antes do curso eletivo.

\begin{tabular}{lccc}
\hline Comparação das pontuações & $\mathrm{n}(\%)$ & $\mathrm{n}(\%)$ & valor $\boldsymbol{p}$ \\
\hline PANAS pos. atenção & $11,00(2,19)$ & $11,07(3,22)$ & 0,894 \\
PANAS negativo & $19,94(8,01)$ & $22,43(5,04)$ & 0,366 \\
PANAS neg. medo & $10,31(3,91)$ & $11,71(2,70)$ & 0,315 \\
PANAS neg. hostilidade & $12,31(5,89)$ & $12,64(4,27)$ & 0,956 \\
PANAS neg. culpa & $10,13(5,08)$ & $12,14(4,22)$ & 0,329 \\
PANAS neg. tristeza & $9,06(5,22)$ & $12,14(5,23)$ & 0,115 \\
OMS 5 & $12,44(4,27)$ & $11,50(5,02)$ & 0,507 \\
MAAS & $59,69(10,28)$ & $50,71(9,06)$ & 0,028 \\
PPS & $21,19(6,98)$ & $25,00(6,03)$ & 0,144 \\
\hline
\end{tabular}

* Teste T de Student; EP - erro padrão; n- número de participantes; MAAS- Escala de Atenção Plena e Consciência; PANAS- Escala de Afeto Negativo e Positivo; OMS 5- Índice de Bem-Estar; PSS - Escala de Estresse Percebido

nenhuma das variáveis entre o primeiro e o segundo momento, $\mathrm{F}(11)=1,375, \mathrm{p}=0,268, \eta 2=0,223$, $\mathrm{PO}=0,400$. Por outro lado, os testes univariados indicaram um efeito do curso eletivo no total negativo do PANAS-X, bem como nos aspectos Medo e Hostilidade da escala, ao comparar o primeiro e o segundo momento $(\mathrm{p}<0,05)$ (Tabela 3$)$. Nenhuma outra diferença significativa foi detectada.

\section{Resultados qualitativos}

O enfrentamento das dificuldades diárias foi um dos principais motivos para a escolha do curso eletivo pelos alunos. Os participantes do curso afirmaram que buscavam autoconhecimento e autocontrole. Vários deles se queixaram de falta de concentração e número excessivo de atividades. Três categorias temáticas emergiram: (a) dificuldades em viver o momento presente e ansiedade na tentativa de controlar o futuro; (b) práticas de meditação como uma ferramenta para enfrentar tais dificuldades; e (c) experiência caracterizada pelo afeto.

\section{(a) Dificuldades em viver o momento presente e ansiedade na tentativa de controlar o futuro}

Esta categoria foi baseada na pergunta sobre como os alunos se percebem emocionalmente. Os alunos mencionaram dificuldades em estar presente a cada momento e demonstraram preocupaçóes com os próximos dias e futuros compromissos, o que causou estresse, ansiedade e falta de tolerância consigo e com os outros.

Aluno 8: "Não consigo viver um dia de cada vez, simplesmente não consigo, estou aqui, mas minha cabeça está divagando sobre tudo o que farei amanhã, sobre como vou encontrar tempo para fazer as coisas".

Aluno 9: "Também sou uma pessoa muito ansiosa. Náo consigo viver um dia de cada vez, estou sempre pensando se algo vai dar certo, se não der certo, o que eu vou fazer, que eu preciso ter um plano $\mathrm{B}$, caso contrário, não consigo me organizar”.

Aluno 10: "Também sou muito ansioso, fui para terapia por causa dessa condição, mas ainda sou assim, náo consigo pensar no momento presente, agora estou pensando em outras coisas. Esse ano foi muito estressante".

Ao final do curso eletivo, os alunos foram entrevistados pela segunda vez. Foi solicitado então que avaliassem o curso e relatassem as mudanças percebidas nas emoçóes, se as expectativas tinham sido atendidas e se achavam que o curso deveria ser obrigatório no currículo, como um investimento na saúde integral dos futuros profissionais de saúde. As duas categorias a seguir foram identificadas.

Tabela 3. Comparação das pontuações obtidas nos grupos de estudo e controle antes (T0) e depois (T1) do curso eletivo.

\begin{tabular}{|c|c|c|c|c|c|c|c|}
\hline & \multicolumn{2}{|c|}{ grupo de estudo ( $n=16$ ) } & \multicolumn{2}{|c|}{ Grupo de controle $(n=14)$} & \multirow{3}{*}{$\begin{array}{c}\text { Efeito Tempo X } \\
\text { Grupo } \\
\text { Valor } \mathrm{p}\end{array}$} & \multirow{3}{*}{ Tamanho do efeito } & \multirow{3}{*}{ Potência observada } \\
\hline & T0 & $\mathrm{T} 1$ & T0 & $\mathrm{T} 1$ & & & \\
\hline & Média (DP) & Média (DP) & Média (DP) & Média (DP) & & & \\
\hline PANAS positivo & $28,13(5,97)$ & $27,94(7,28)$ & $27,43(6,30)$ & $26,86(4,96)$ & 0,878 & 0,001 & 0,053 \\
\hline PANAS pos. Jovialidade & $21,13(6,27)$ & $23,69(5,30)$ & $19,93(7,70)$ & $20,71(5,31)$ & 0,495 & 0,017 & 0,103 \\
\hline PANAS pos. Autoconfiança & $15,81(4,05)$ & $15,56(4,62)$ & $14,43(3,39)$ & $14,21(3,49)$ & 0,980 & $<0,001$ & 0,050 \\
\hline PANAS pos. Atenção & $11,00(2,19)$ & $11,62(3,03)$ & $11,07(3,22)$ & $11,21(1,25)$ & 0,706 & 0,005 & 0,066 \\
\hline PANAS Negativo & $19,94(8,01)$ & $17,50(3,97)$ & $22,43(5,04)$ & $27,29(7,93)$ & $0,017^{*}$ & 0,118 & 0,690 \\
\hline PANAS neg. Medo & $10,31(3,91)$ & $9,69(2,12)$ & $11,71(2,70)$ & $14,79(5,67)$ & $0,042^{*}$ & 0,140 & 0,540 \\
\hline PANAS neg. Hostilidade & $12,31(5,89)$ & $10,00(3,10)$ & $12,64(4,27)$ & $16,00(5,71)$ & $0,023^{*}$ & 0,171 & 0,642 \\
\hline PANAS Neg. Culpa & $10,13(5,08)$ & $10,00(4,31)$ & $12,14(4,22)$ & $14,86(6,76)$ & 0,131 & 0,080 & 0,325 \\
\hline PANAS neg. Tristeza & $9,06(5,22)$ & $9,00(3,60)$ & $12,14(5,23)$ & $13,43(4,88)$ & 0,515 & 0,015 & 0,098 \\
\hline OMS 5 & $12,44(4,27)$ & $14,56(3,22)$ & $11,50(5,02)$ & $11,43(3,48)$ & 0,176 & 0,064 & 0,269 \\
\hline MAAS & $59,69(10,28)$ & $59,06(10,99)$ & $50,71(9,06)$ & $48,86(9,13)$ & 0,799 & 0,002 & 0,057 \\
\hline PSS & $21,19(6,98)$ & $16,63(4,95)$ & $25,00(6,03)$ & $24,50(4,47)$ & 0,129 & 0,080 & 0,326 \\
\hline
\end{tabular}

${ }^{*} \mathrm{p}<0,05 ; \mathrm{n}$ - número de participantes; T0- momento antes do curso eletivo; $\mathrm{T} 1$ - momento após o curso eletivo; Tamanho do efeito - Eta ao quadrado parcial (menos de 0,01 indica um tamanho do efeito pequeno; 0,06 indica um tamanho do efeito médio; maior que 0,14 indica um tamanho do efeito grande) 


\section{(b) Práticas de meditaçáo como uma ferramenta para enfrentar tais dificuldades}

Os alunos disseram se sentir mais calmos ao longo do curso e mais concentrados no momento presente. Conseguiram identificar situaçóes que causavam sofrimento emocional e tentaram lidar com essas situaçôes pela meditação.

Aluno 1: "Ajudou muito, me sinto mais focado e consegui realizar as atividades (...). Também estou me sentindo mais calmo".

Aluno 14: "Usei a prática meditativa quando senti a necessidade, por exemplo: Eu estou muito agitado ou pensando em mais de uma coisa ao mesmo tempo e sei que náo poderei dar conta de tudo. Então, eu vou parar e pensar uma coisa de cada vez".

Aluno 21: "Um dia, eu estava no laboratório e adormeci, e minha caixa de luvas simplesmente desapareceu. Fiquei com muita raiva. Então, eu tinha dois caminhos a seguir: eu podia explodir, descontar nas pessoas que não tinham nada a ver com isso, ou respirar fundo. Fui ao pequeno pátio em frente ao laboratório, sentei e pensei: 'Agora vamos ver se funciona'. Comecei a contar as minhas respirações. Novamente, não foi uma mudança brutal e completa, mas apenas o fato de ter conseguido me controlar e não descontar nas pessoas, bem, já foi alguma coisa. Foi uma experiência muito positiva que renovou meus ideais e minha crença na meditação. Pensei: 'Olha só, esse é um exemplo prático onde realmente funcionou'”.

\section{(c) Experiência caracterizada por afeto}

Essa categoria analítica se baseou na relação aluno -professor e no espaço de gentileza promovido pelo professor, o que contribuiu para uma avaliação positiva da disciplina.

Aluno 4: "O curso eletivo foi além das minhas expectativas (...) Foi totalmente diferente, foi muito bom estar aqui e receber um abraço do professor. Ser acolhido por todos, acho que me fez ver as coisas de maneira diferente".

Aluno 14: "Achei o projeto muito interessante. Acho que a atmosfera contribuiu, assim como o professor, sempre muito gentil. Essas coisas nos ajudaram a continuar participando. Eu queria estar aqui, mesmo tendo que acordar cedo para chegar aqui. Não foi algo que fiz porque era necessário, eu senti vontade de participar. Eu me sinto diferente em relação a outros cursos, achei muito útil, gostei muito".

Aluna 17: "Gostei muito da professora, ela realmente me mostrou a gentileza das pessoas. Porque ela era gentil sem motivo, e isso era muito legal. Eu não esperava, muito menos de um professor. Estamos táo acostumados com os professores que nem sabemos o nome, e eles não sabem o nosso, e não temos nenhum contato. Legal, foi muito legal".

Os registros no diário de campo mostraram que três estudantes de Medicina não estavam motivados a prosseguir com as atividades propostas em sala de aula. Eles lentamente se tornaram mais integrados e, quando apresentaram sua opinião acerca do tema do seminário sobre espiritualidade e saúde integral, a classe teve uma agradável surpresa. Foi visível que eles tinham dedicado tempo ao livro, expressaram ideias profundas e fizeram reflexóes e conexôes com suas vidas.

As apresentaçóes dos alunos sobre os livros assumiram a forma de seminário, em que mostraram compreensão ampla e profunda do conteúdo usado nos exercícios. Os alunos se tratavam cordial e respeitosamente em todas as aulas. Todos foram capazes de realizar as práticas de meditação de atenção plena durante as aulas. No início, eles se sentiram envergonhados com os exercícios e defensivos em relação aos colegas, mas aos poucos relaxaram. Eles se sentiram bem-vindos na classe, o que melhorou ainda mais a frequência.

\section{Discussão}

Nossa hipótese foi que um curso eletivo sobre práticas de meditação de atenção plena, baseadas na espiritualidade e na neurociência, promoveria a saúde integral dos alunos e teria efeitos mentais benéficos. Nossos resultados confirmaram a hipótese, revelando que os participantes do curso eletivo reduziram o afeto negativo, especificamente medo e hostilidade, de acordo com achados anteriores. ${ }^{(8,21,22)} \mathrm{O}$ curso eletivo impactou significativamente o medo e a hostilidade entre os afetos negativos. Detectamos 
que as aulas proporcionaram um ambiente seguro e gentil, possibilitando aos alunos superar aqueles sentimentos. O mesmo não foi observado no grupo de controle, cujo medo e hostilidade aumentaram entre o início e o final da disciplina.

O efeito sobre os afetos negativos é especialmente relevante porque os processos neurológicos no cérebro humano os estimulam mais facilmente em comparação com os afetos positivos. Os afetos negativos induzem a um aprendizado mais rápido e desaparecem mais lentamente ante os afetos positivos, interferindo mais fortemente no julgamento e na tomada de decisóes. $\mathrm{O}$ viés negativo do cérebro tem uma função evolutiva essencial para evitar o perigo e desenvolver funçóes sociais e cognitivas. ${ }^{(23)}$

O medo é uma emoção primária. Todos os seres humanos o experimentam desde a infância por meio de um mecanismo pré-organizado, que permite nossas reaçóes a perigos ou ameaças. $\mathrm{O}$ medo se desenvolve cedo e resiste à mudança. ${ }^{(24)}$ Pode paralisar um indivíduo que tentará escapar e evitar o enfrentamento de diferentes situações. Estímulos como segurança podem reverter essa emoção primitiva. Nosso curso eletivo proporcionou um ambiente seguro, reforçado pela atitude compassiva do professor e pela própria essência da prática meditativa.

Por outro lado, a hostilidade é uma emoção secundária ou social que os humanos desenvolvem em suas vidas através de trocas sociais e culturais. $\mathrm{O}$ curso eletivo incluiu preceitos budistas de compaixão e gentileza, que podem modular a hostilidade. A compaixáo coloca os indivíduos no mesmo nível e traz a compreensão de que o outro também anseia por felicidade e tenta evitar o sofrimento.

Praticar a compaixão e a autocompaixão demanda reconhecer o próprio sofrimento, erros, escapadas e todos os sentimentos negativos associados evocados durante esses processos. Somente assim um indivíduo pode, de forma gentil, evitar se fixar em caminhos que conduzam ao sofrimento sem negá-lo ou tentar encontrar culpados de maneira não julgadora. ${ }^{(25)}$

Um estudo recente mencionou que "uma mente que vagueia é uma mente infeliz", porque quando a mente humana fica à deriva, ela tende a se concentrar em experiências negativas. ${ }^{(26)}$ Quando os alunos têm dificuldade em viver o momento presente, tendem a aumentar seu nível de sofrimento emocional. Mesmo que o instrumento de avaliação da atenção (MAAS) não tenha mostrado um resultado significativo, os alunos relataram que sentem quando suas mentes dispersam, seja por pensar em muitas coisas ao mesmo tempo ou ao tentar resolver problemas que ainda não aconteceram. As práticas do curso ajudaram a modular as emoçôes desconfortáveis relacionadas à dispersão mental.

Durante a segunda e última entrevista, os alunos que participaram do curso tiveram um comportamento mais calmo, as declaraçóes indicaram que aceitavam suas dificuldades e limitaçóes com mais facilidade e percebiam suas emoçóes com mais intensidade. Esses indivíduos também relataram enfrentar situaçôes estressantes de maneira menos agitada. Com frequência, eles usaram a meditação nesses processos, o que os levou a resolver o problema com calma ou a aceitar a falta de soluçáo de maneira autocompassiva.

Os participantes do estudo revelaram a profundidade com que sentiram a gentileza e atenção da professora com eles e valorizaram possuir um espaço onde ela os ouvia atentamente. A terceira categoria analítica forneceu evidências da surpresa dos alunos com o comportamento acessível e gentil do professor. A atitude do corpo docente estimulou a participaçáo dos alunos no curso e renovou sua crença em um relacionamento afetuoso entre alunos e professores. Diversos estudos anteriores focados no intercâmbio entre alunos e professores indicaram que o tipo de atenção dedicada aos indivíduos ou ao grupo pode promover ou corroer um ambiente de aprendizado. $\mathrm{O}$ respeito e a cordialidade com os alunos potencializam a confiança, o diálogo, o apoio e a orientação e resultam em melhor educação. ${ }^{(27,28)}$

Em um estudo prévio, foi investigada uma associação putativa entre a atitude do corpo docente e uma experiência positiva de aprendizagem. Os autores concluíram que as dimensôes afetivas não podem ser separadas da inteligência, pois ambas evoluem em paralelo. Os professores devem se apoiar nos aspectos afetivos e cognitivos da Educação para promover uma experiência positiva de aprendizagem. ${ }^{(28)}$ 
Assim, para a implementação de tal disciplina no curso de graduação, é preciso pensar que o papel do professor vai além do ensino de técnicas de meditação e faz parte do próprio método, com envolvimento pessoal e devida atenção aos alunos.

Este foi um estudo exploratório. Por se tratar de uma amostra de conveniência, o número reduzido de participantes teve implicaçôes nos resultados quantitativos. Idealmente, estudantes em um grupo de controle fariam um curso diferente, mas com as mesmas intençôes, como o curso de meditação descrito aqui. No presente estudo, além do tamanho pequeno da amostra, ainda houve influência do fato de alguns alunos não realizarem todas as práticas de meditação propostas. Futuros estudos envolvendo coortes maiores podem trazer à luz outros aspectos positivos da inclusão de práticas de meditação de atenção plena no currículo da atenção à saúde.

Outro ponto importante foi que o professor conduziu a entrevista, o que levou a uma reflexão sobre uma possível interferência na avaliação do curso. Embora os comentários dos estudantes não fossem obrigatórios, todos relataram suas experiências espontaneamente. $\mathrm{O}$ curso está no quinto ano atualmente e as entrevistas não foram conduzidas pelo professor responsável, e os resultados foram muito semelhantes.

Pode haver um viés, embora não possamos entender neste caso, pois acreditamos que o professor realmente influenciou no resultado do curso e teve relação com o processo de condução da disciplina e construção do vínculo de confiança com os alunos.

\section{Conclusão}

O curso eletivo focado na meditação da atenção plena e compaixão desenvolveu habilidades socioemocionais, de bem-estar e autoconsciência dos alunos, além de reduzir o afeto negativo. Os indivíduos do grupo de estudo relataram os efeitos benéficos da meditação na redução da ansiedade e apresentaram escores mais baixos no afeto negativo, especificamente medo e hostilidade. $\mathrm{O}$ estresse percebido também foi menor entre esses estudantes, que descobriram a origem de sua ansiedade na dificuldade de viver o momento presente e constante antecipação de problemas futuros. Eles se tornaram mais conscientes de suas emoçóes e perceberam a importância de saber como lidar com elas e aceitá-las.

\section{Colaborações}

Araujo AC, Santana CLA, Kazasa EH, Lacerda SS e Tanaka LH contribuíram com o desenho do estudo, análise e interpretação dos dados, redação do artigo, revisão crítica do conteúdo intelectual e aprovação da versão final a ser publicada.

\section{Referências}

1. Gramstad T0, Gjestad R, Haver B. Personality traits predict job stress, depression and anxiety among junior physicians. BMC Med Educ. 2013;13(1):150.

2. Basnet B, Jaiswal M, Adhikari B, Shyangwa PM. Depression among undergraduate medical students [KUMJ]. Kathmandu Univ Med J (KUMJ). 2012;10(39):56-9.

3. Ibrahim NK, Battarjee WF, Almehmadi SA. Prevalence and predictors of irritable bowel syndrome among medical students and interns in King Abdulaziz University, Jeddah. Libyan J Med. 2013;8(1):21287.

4. Bampi LN, Baraldi S, Guilhem D, Pompeu RB, Campos AC. Nurse undergraduate students' perception of quality of life] Rev Gaúcha Enferm. 2013;34(2):125-32.

5. Mazzaia MC, Santos RM. Fatores de risco para transtornos alimentares em graduandos de enfermagem. Acta Paul Enferm. 2018;31(5):45662.

6. World Health Organization (WHO). Promoting mental health: concepts, emerging evidence, practice: summary report [Internet]. Geneva: WHO; 2004. p. 68. [cited 2019 0ct 19]. Available from: http://WwwWholnt/ Mental_Health/Evidence/En/Promoting_MhhPdf.

7. Kabat-Zinn J. Mindfulness-based interventions in context: past, present, and future. Clin Psychol Sci Pract. 2003;10(2):144-56.

8. Keng SL, Smoski MJ, Robins CJ. Effects of mindfulness on psychological health: a review of empirical studies. Clin Psychol Rev. 2011;31(6):1041-56.

9. Rios IC, Sirino CB. A Humanização no ensino de graduação em medicina: 0 olhar dos estudantes. Rev Bras Educ Med. 2015;39(3):401-9.

10. Dobkin PL, Hutchinson TA. Teaching mindfulness in medical school: where are we now and where are we going? Med Educ. 2013;47(8):768-79.

11. Correia HM, Smith AD, Murray S, Polak LS, Williams B, Cake MA. The Impact of a Brief Embedded Mindfulness-Based Program for Veterinary Students. J Vet Med Educ. 2017;44(1):125-33. 
12. Sanko J, Mckay M, Rogers S. Exploring the impact of mindfulness meditation training in pre-licensure and post graduate nurses. Nurse Educ Today. 2016;45:142-7.

13. Kelly M. Does Mindfulness practice improve the mental health and wellbeing of healthcare students? J Psychiatr Ment Health Nurs. 2017;24(1):84-9.

14. Walker $M$, Mann RA. Exploration of mindfulness in relation to compassion, empathy and reflection within nursing education. Nurse Educ Today. 2016;40:188-90.

15. Yin RK. Estudo de caso: planejamento e métodos. [Trad. Daniel Grassi]. 3a ed. Porto Alegre: Bookman; 2005.

16. Zanon C, Bastianello MR, Pacico JC. Development and validation of a positive and negative affect scal. Psico-USF. (Bragança Paullista). 2013;18(2):193-202.

17. de Barros WV, Kozasa EH, de Souza IC, et al. Validity evidence of the brazilian version of the Mindful Attention Awareness Scale (MAAS). Psicol Reflex Crit. 2015;28(1):87-95.

18. Reis RS, Hino AA, Añez CR. Perceived stress scale: reliability and validity study in Brazil. J Health Psychol. 2010;15(1):107-14.

19. Topp CW, Østergaard SD, Søndergaard S, Bech P. The WHO-5 Well-Being Index: a systematic review of the literature. Psychother Psychosom. 2015;84(3):167-76.

20. Sampire RH, Collado CF. Lucio MD. Metolologia da pesquisa. Coleta e análise de dados qualitativos. [Trad. Daisy de Moraes]. 3a ed. Porto Alegre: Penso; 2013. p.418-40.
21. McConville J, McAleer R, Hahne A. Mindfulness Training for Health Profession Students-The Effect of Mindfulness Training on Psychological Well-Being, Learning and Clinical Performance of Health Professional Students: A Systematic Review of Randomized and Nonrandomized Controlled Trials. Explore (NY). 2017;13(1):26-45.

22. Kinser $P$, Braun S, Deeb G, Carrico C, Dow A. "Awareness is the first step": an interprofessional course on mindfulness \& mindfulmovement for healthcare professionals and students. Complement Ther Clin Pract. 2016;25:18-25.

23. Vaish A, Grossmann T, Woodward A. Not all emotions are created equal: the negativity bias in social-emotional development. Psychol Bull. 2008;134(3):383-403.

24. Hartley CA, Phelps EA. Changing fear: the neurocircuitry of emotion regulation. Neuropsychopharmacology. 2010;35(1):136-46.

25. Souza LK, Hutz CS. Adaptation of the Self-Compassion Scale for use in Brazil: evidences of construct validity. Temas Psicol. 2016;24(1):159-72.

26. Killingsworth MA, Gilbert DT. A wandering mind is an unhappy mind. Science. 2010;330(6006):932.

27. Olave P G, Pérez V C, Fasce H E, Ortiz M L, Bastías V N, Márquez $\mathrm{U} C$, et al. Factores que afectan al ambiente educativo en la formación preclínica de medicina según sus docentes. Rev Med Chil. 2016;144(10):1343-50.

28. Veras RS, Ferreira SP. A afetividade na relação professor-aluno e suas implicações na aprendizagem, em contexto universitário. Educ Rev. 2010;(38):219-35.

\section{Apêndice 1. Programa do curso}

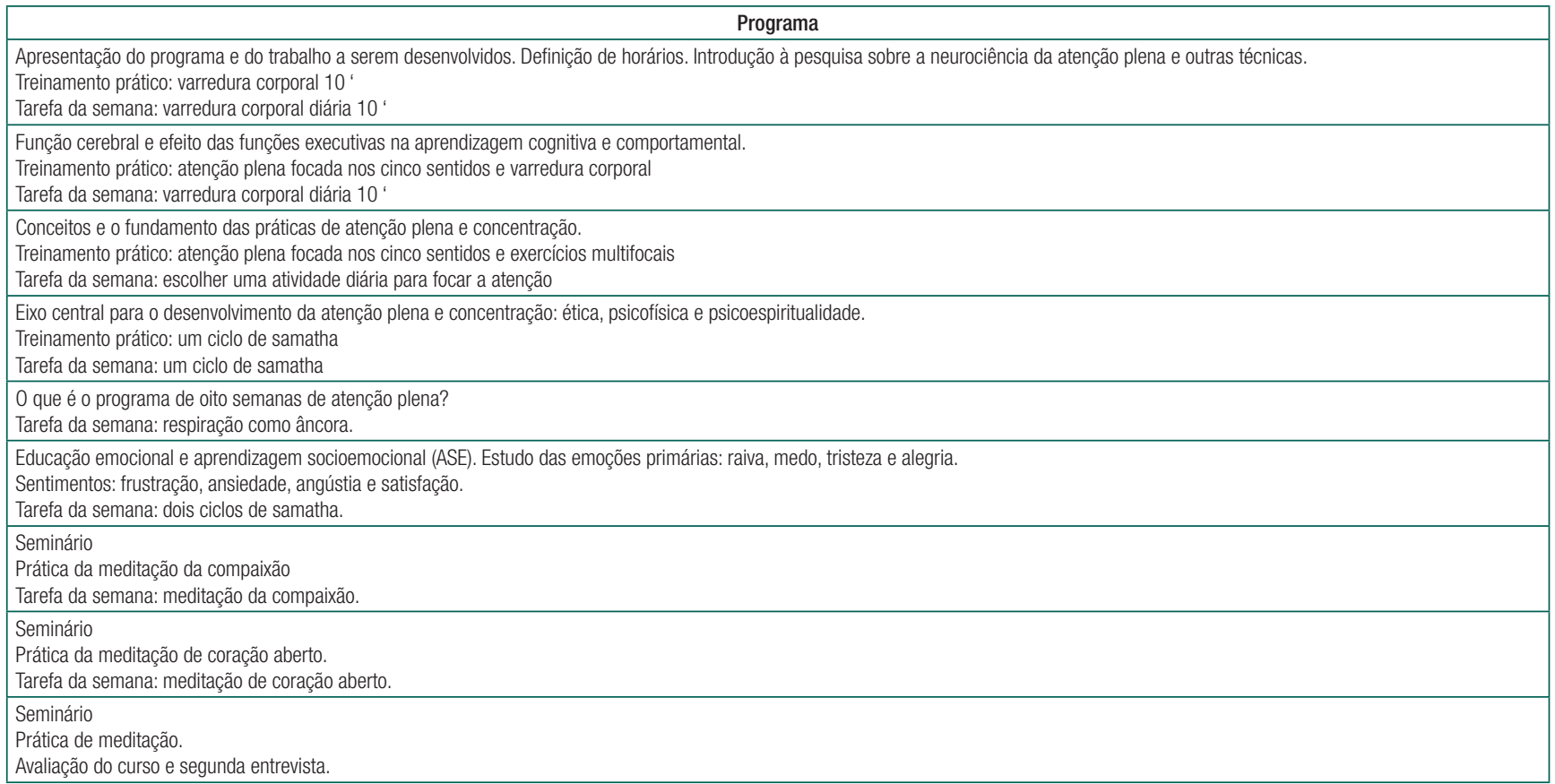

